\title{
Study on Stability of Round Tunnel Surrounding Rock
}

\author{
NIU Yan ${ }^{1,2,3,4 \cdot a}$, Ji Yafei ${ }^{2}$, Wang Zhao ${ }^{1,2,3,4}$ \\ ${ }^{1}$ Institute of Land Engineering and Technology, Shaanxi Provincial Land Engineering Construction Group Co., Ltd. Xi’an 710075; \\ ${ }^{2}$ Shaanxi Provincial Land Engineering Construction Group Co., Ltd. Xi'an 710075; \\ ${ }^{3}$ Key Laboratory of Degraded and Unused Land Consolidation Engineering, the Ministry of Land and Resources Xi'an 710075; \\ ${ }^{4}$ Shaanxi Provincial Land Consolidation Engineering Technology Research Center Xi'an 710075
}

\begin{abstract}
Tunnel excavation will lead to the immediate surrounding rock unloading caused by the surrounding rock stress release, the stability of the surrounding rock have a certain impact. In this paper, finite element software ANSYS and finite difference software FLAC3D are used to simulate the excavation and lining process of circular tunnel. The influence of excavation on the rock stability around circular tunnel is analyzed, and the effect of applying lining on the stability of surrounding rock is analyzed. Evaluation criteria selection hole displacement, stress and plastic area of three factors.
\end{abstract}

\section{Introduction}

In the case of larger buried depth and lower strength of surrounding rock, some tunneling measures should be applied to ensure the stability of the surrounding rock. The lining is to enhance the stability of the tunnel. The use of reinforced concrete and other materials in the tunnel A protective layer built around the tunnel. ${ }^{[1 \sim 2]}$

Lining construction on the one hand can enhance the stability of the tunnel and the surrounding rock mass, on the other hand can also prevent contact with the rock mass outside the tunnel to form a barrier to isolate water and air, to prevent water or air erosion, weathering ; The formation of a smooth wet weeks, so that the roughness decreases, improve the surrounding water flow, so that cross-sectional flow unit increases, reducing the unit cost of the tunnel; formation of aqueduct to reduce tunnel and surrounding rock mutual seepage; bearing Wai Rock external load, internal load and so on. It is one of the hot spots in underground engineering to study the influence of tunnel lining on the stability of surrounding rock through numerical simulation.

\section{Project Overview}

A hydropower station is a single-target project that takes power generation as its task. It is a third-stage hydropower station cascaded and developed in the basin of Podratun Zangbo. Its dam drainage area is $2453 \mathrm{~km}^{2}$ with annual average flow of $132 \mathrm{~m}^{3} / \mathrm{s}$. Spillway structures are mainly cave spillway and spillway tunnel (and diversion tunnel). The total length of the spillway tunnel is $\mathbf{5 3 6 . 6 6}$ meters, which is a circular tunnel with a diameter of 10 meters. The diversion period is made of

\footnotetext{
Corresponding author: ${ }^{a}$ Niu Yan: $2330517641 @$ qq.com
}

cast-in-place concrete lining, with a lining thickness of 0.8 meters and faults and broken belts. The lower part of station $0+120$ to $0+320$ is Grade III rock, the upper part is Grade IV rock, and the fault and fracture zone are Grade V rock. ${ }^{[3 \sim 7]}$

\section{Three - dimensional numerical model and calculation parameters selection}

The section of the tunnel is circular with a diameter of 10 $\mathrm{m}$ and a depth of $400 \mathrm{~m}$. The model range in the direction of the vertical axis is larger than 5 times the diameter of the tunnel. The Y-axis is parallel to the axis of the tunnel, the $\mathrm{X}$-axis is vertical upward, and is modeled by ANSYS software. The mesh is solid element SOLID45, which is divided into 116906 units with 123,283 nodes.

The bottom of the model constrains the three-way displacement and the horizontal displacement around the constraint. The top model is established to the surface to simulate the self-weight of the upper rock mass. The rock mass is mainly composed of Group III and IV rock mass, and the fault and broken belt are Grade V rock. The lining is $\mathrm{C} 40$ concrete. The mechanical parameters of III, IV and V rock and concrete are shown in Table 1.

FLAC3D software calculation of bulk modulus and shear modulus parameters of the formula ${ }^{[8-9]}$ :

$$
\begin{aligned}
& \text { Bulk modulus } \mathrm{K}=\mathrm{E} /[3(1-2 \mu)] \\
& \text { Shear modulus } \mathrm{G}=\mathrm{E} /[2(1+\mu)]
\end{aligned}
$$

Table 1 The mechanical parameters of the material

\begin{tabular}{|l|l|l|}
\hline & type of rock & Concrete \\
\hline
\end{tabular}




\begin{tabular}{|c|c|c|c|c|}
\hline & III & IV & V & C40 \\
\hline $\begin{array}{c}\text { density } \\
\rho\left(\mathrm{g} / \mathrm{cm}^{3}\right)\end{array}$ & 2650 & 2450 & 2250 & 2400 \\
\hline $\begin{array}{c}\text { Elastic Modulus } \\
\text { E(Gpa) }\end{array}$ & 8 & 5 & 1.2 & 32.5 \\
\hline $\begin{array}{c}\text { Poisson's ratio } \\
\mu\end{array}$ & 0.25 & 0.3 & 0.4 & 0.2 \\
\hline $\begin{array}{c}\text { tensile strength } \\
\text { R (Mpa })\end{array}$ & 2.2 & 2 & 1.5 & 1.71 \\
\hline $\begin{array}{c}\text { Cohesion } \\
\mathrm{c}(\text { Mpa })\end{array}$ & 1.1 & 0.5 & 0.2 & - \\
\hline $\begin{array}{c}\text { Friction angle } \\
\varphi(0)\end{array}$ & 47.4 & 35 & 25 & - \\
\hline
\end{tabular}

\section{Result analysis}

\subsection{Initial stress field}

In the field of underground engineering, the existence and influence of initial geostress field can not be neglected. It is not only an important controlling factor that affects the mechanical properties of rock mass, but also one of the most important sources of deformation and destructions under the environmental conditions of rock mass . Therefore, in order to carry out engineering simulation more realistically, it is necessary to ensure the reliability of the initial geostress field. The primary purpose of initial stress field generation is to simulate the existing stress state of surrounding rock and soil before the analysis stage of interest. Figure 1 shows the initial stress field and shows that the indicator is vertical

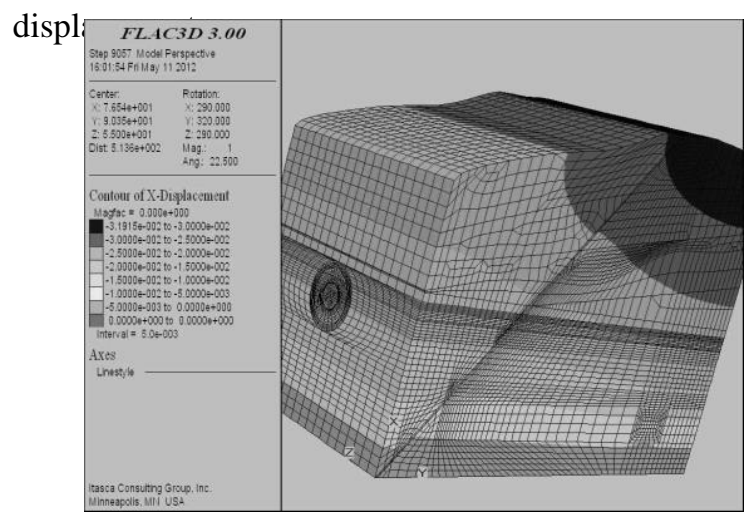

Fig.1 Initial stress field

\subsection{Excavation and lining}

After the initial geostress field is generated, excavation and lining calculation can be performed. Considering the location of faults, the analysis of displacement and stress after excavation and after applying lining mainly considers the following two planes: plane 1 , the point $(0$, $40.62,0)$ is perpendicular to the $y$-axis, that is, the vertical hole axis is close to the fault One side. Surface 2, the point $(0,0,55)$ is perpendicular to the $z$-axis, ie the vertical plane parallel to the axis of the hole.

(1) Displacement and stress

Figures 2 through 9 show the vertical and maximum principal stress maps of the two selected faces after excavation and after application of the lining. Table 2 for the corresponding data sheet.

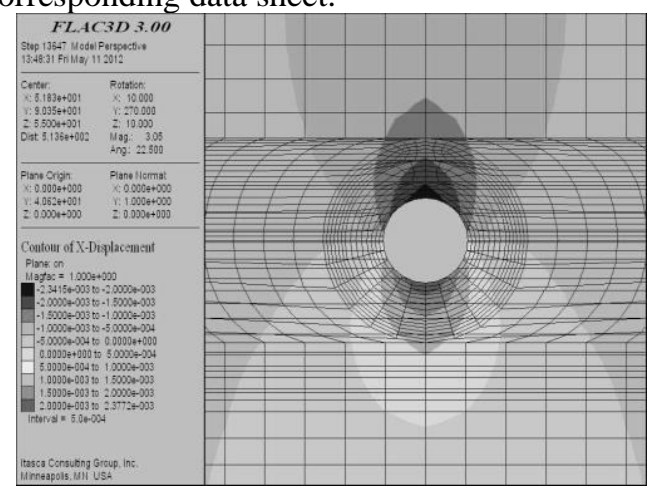

Fig.2 Vertical displacement of flat 1 after excavation
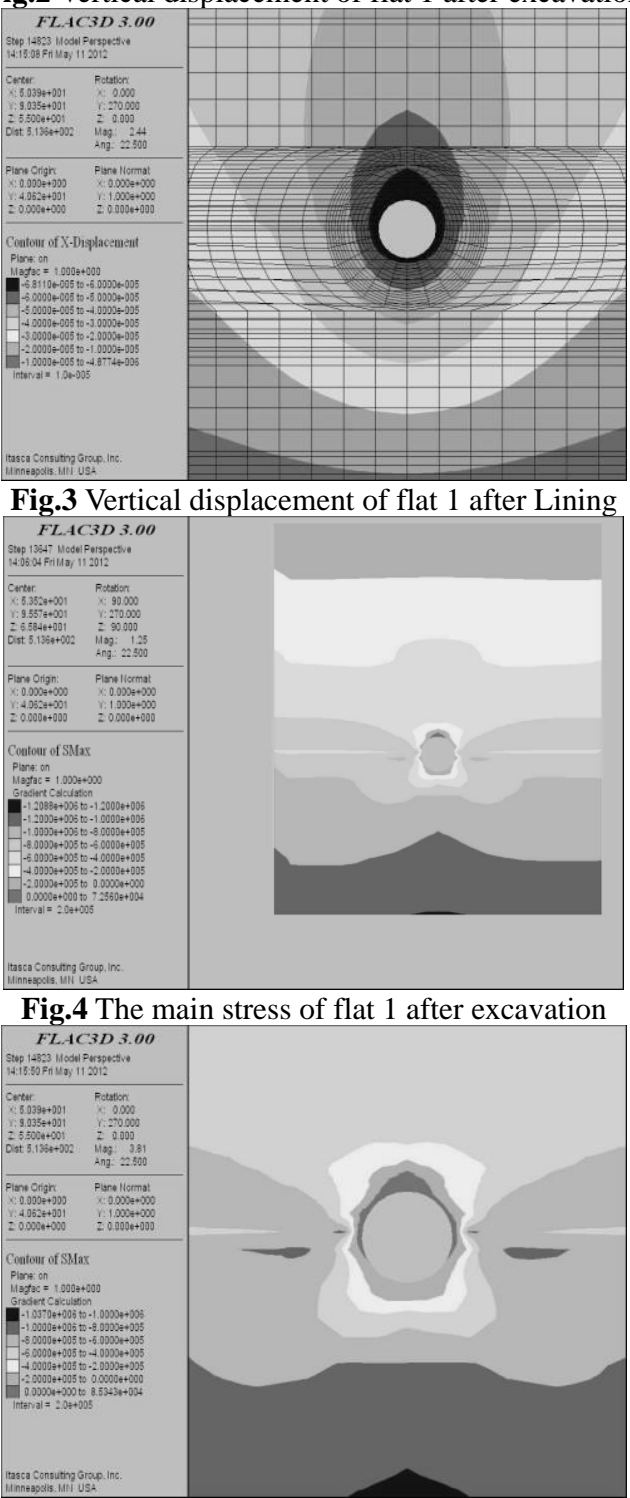

Fig.5 The main stress of flat 1 after Lining 


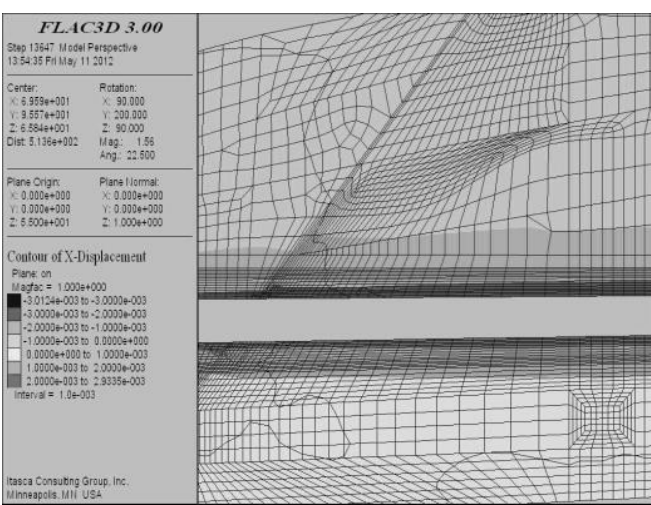

Fig.6 Vertical displacement of flat 2 after excavation

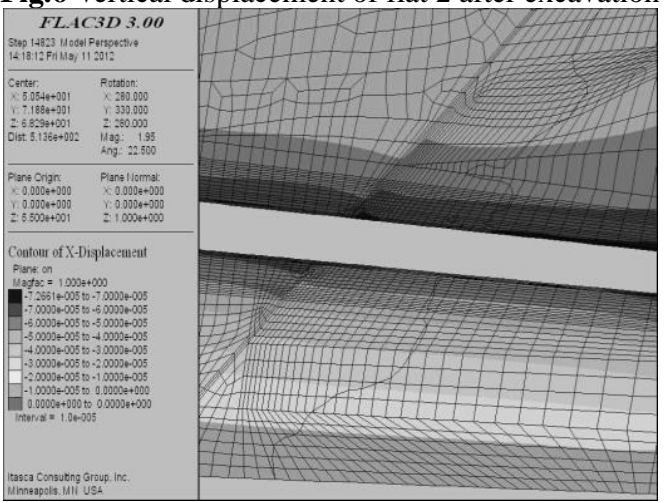

Fig.7 Vertical displacement of flat 2 after Lining

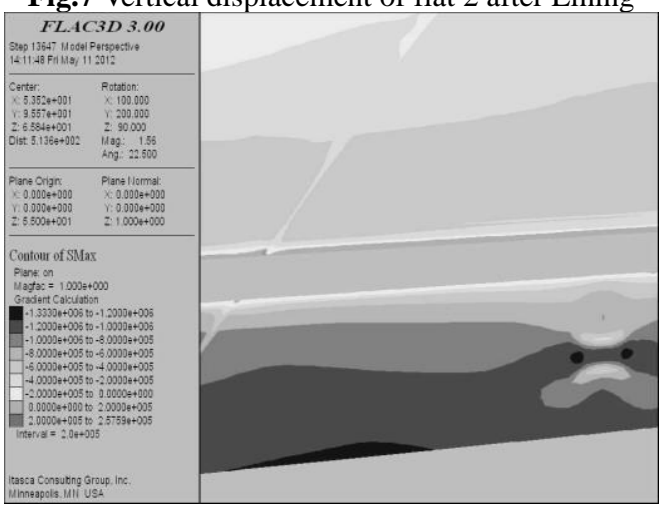

Fig.8 The main stress of flat 2 after excavation

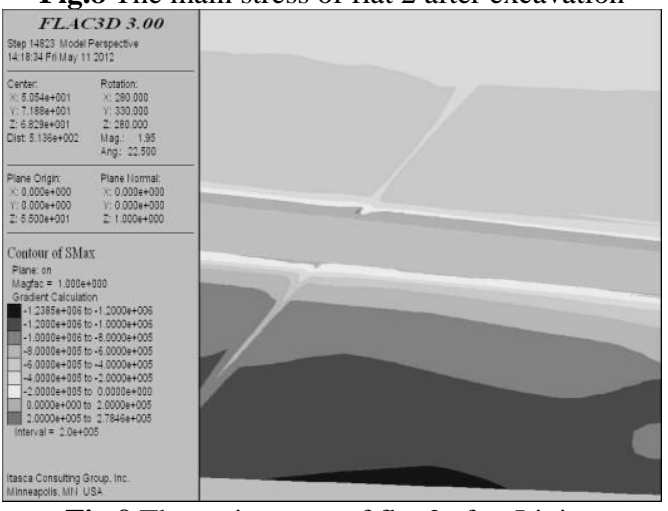

Fig.9 The main stress of flat 2 after Lining

Table.2 After excavation and lining the maximum displacement and the maximum principal stress

\begin{tabular}{|c|c|c|c|}
\hline $\begin{array}{l}\text { Analysis } \\
\text { of the } \\
\text { surface }\end{array}$ & Index & After excavation & $\begin{array}{c}\text { After } \\
\text { lining }\end{array}$ \\
\hline \multirow{2}{*}{ surface 1 } & $\begin{array}{c}\text { Maximum } \\
\text { displacement } \\
(\mathrm{m})\end{array}$ & $\begin{array}{c}\text { Cave top }-2.34 * 10^{-3} \\
\text { Hole bottom } 2.38 * 10^{-3}\end{array}$ & $-6.8 * 10^{-5}$ \\
\cline { 2 - 4 } & $\begin{array}{c}\text { The main } \\
\text { stress (Mpa) }\end{array}$ & -1.21 & -1.04 \\
\hline
\end{tabular}

\begin{tabular}{|c|c|c|c|}
\hline \multirow{3}{*}{ surface 2 } & $\begin{array}{c}\text { Maximum } \\
\text { displacement } \\
(\mathrm{m})\end{array}$ & $\begin{array}{c}\text { Cave top - 3.01*10 } \\
\text { Hole bottom 2.93*10 }\end{array}$ & $\begin{array}{c}-7.27 * \\
10^{-5}\end{array}$ \\
\cline { 2 - 4 } & $\begin{array}{c}\text { The main } \\
\text { stress (Mpa) }\end{array}$ & -1.33 & -1.24 \\
\hline
\end{tabular}

It can be seen from Table 2 that the maximum displacement at the top of the face 1 is $-2.34 * 10^{-3} \mathrm{~m}$, the bottom of the hole is $2.38 * 10^{-3} \mathrm{~m}$, and the maximum displacement after lining is $-6.8 * 10^{-5} \mathrm{~m}$, which shows a significant improvement. The maximum principal stress after excavation is $-1.21 \mathrm{Mpa}$, lining $-1.04 \mathrm{Mpa}$, the stress also improved. The maximum displacement at the top of the surface 2 hole is $-3.01 * 10^{-3} \mathrm{~m}$, the bottom of the hole is $2.93 * 10^{-3} \mathrm{~m}$, and the maximum displacement after lining is $-7.27 * 10^{-5} \mathrm{~m}$, which is obviously improved. The maximum principal stress is $-1.33 \mathrm{Mpa}$ after excavation and $-1.24 \mathrm{Mpa}$ after lining, and the stress is also improved.

\section{(2) Plastic zone}

The plastic zone is the yield zone where the pressure generated by the load around the hole exceeds the ultimate bearing capacity of the surrounding rock and causes the deformation of the local soil to be unrecoverable. Figure 10 to Figure 13 show the plastic zone of the two analyzed surfaces after excavation and after lining It can be seen from the figure that after excavation, the plastic zone around the hole circumference and the fault is larger, but after the lining is applied, the plastic deformation caused by excavation around the tunnel is obviously improved.
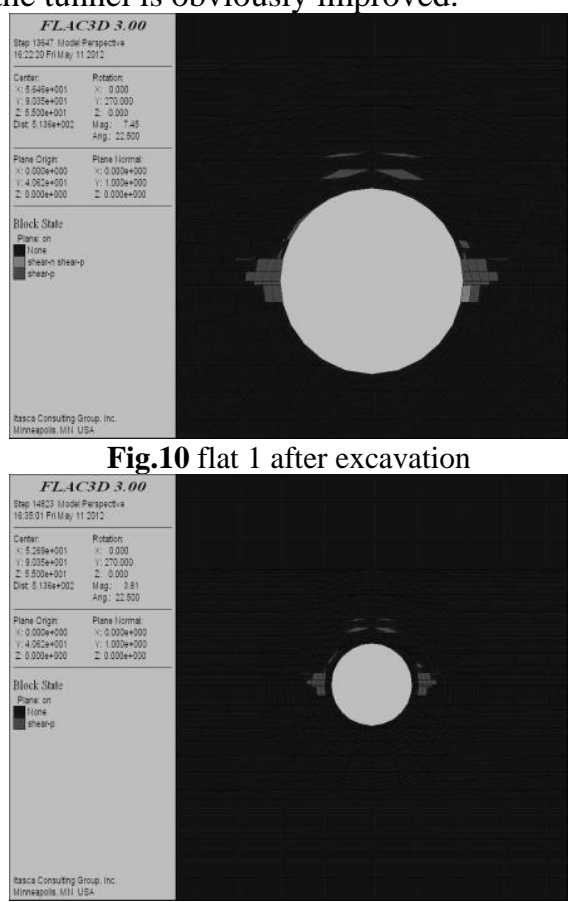

Fig.11 flat 1 after Lining 


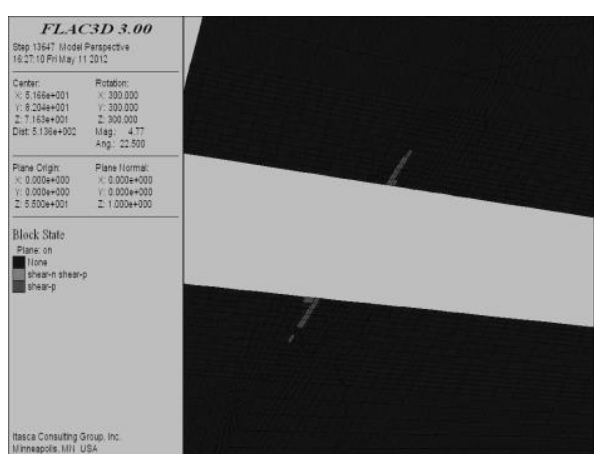

Fig.12 flat 2 after excavation

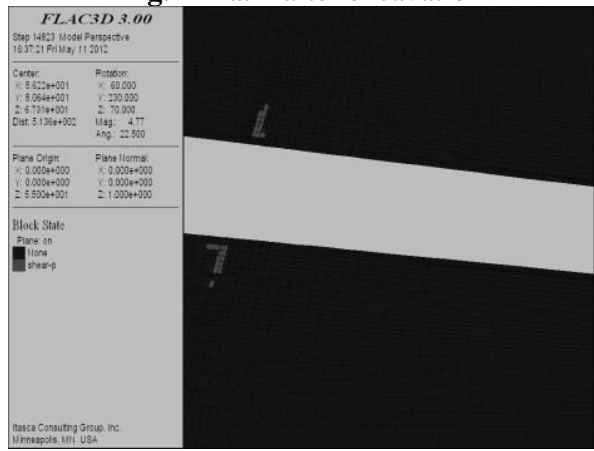

Fig.13 flat 2 after Lining

(3) Variable monitoring

The following variables were monitored during the excavation and lining calculations:

1) Hole bottom away from the center of 5.8 meters, 8 meters, 11 meters, 14 meters at the vertical displacement (followed by black, red, blue, green. The same below)
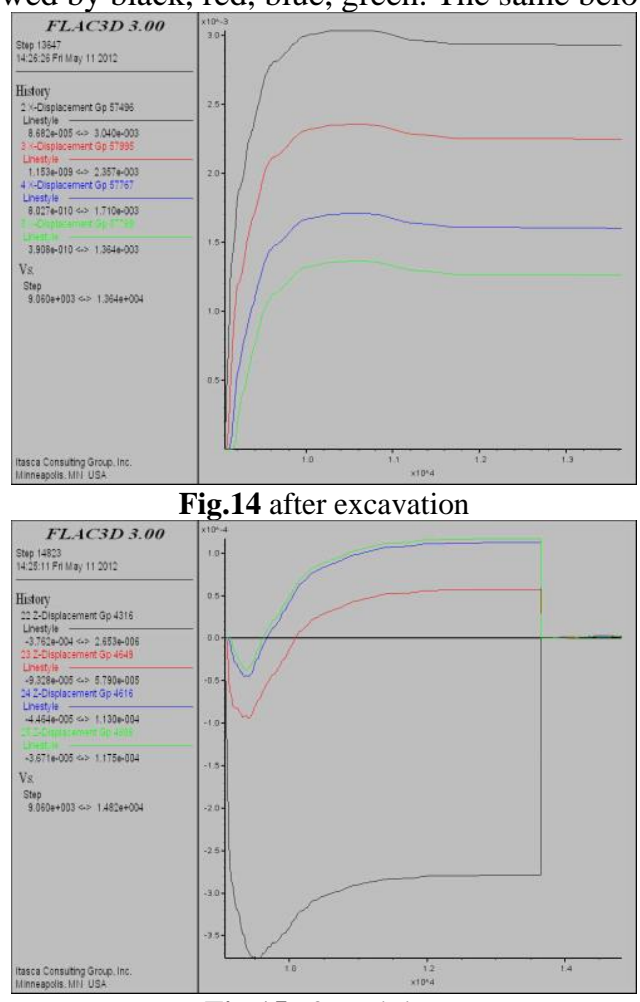

Fig.15 after Lining

2) The roof from the center of the circle 5.8 meters, 8 meters, 11 meters, 14 meters at the vertical displacement

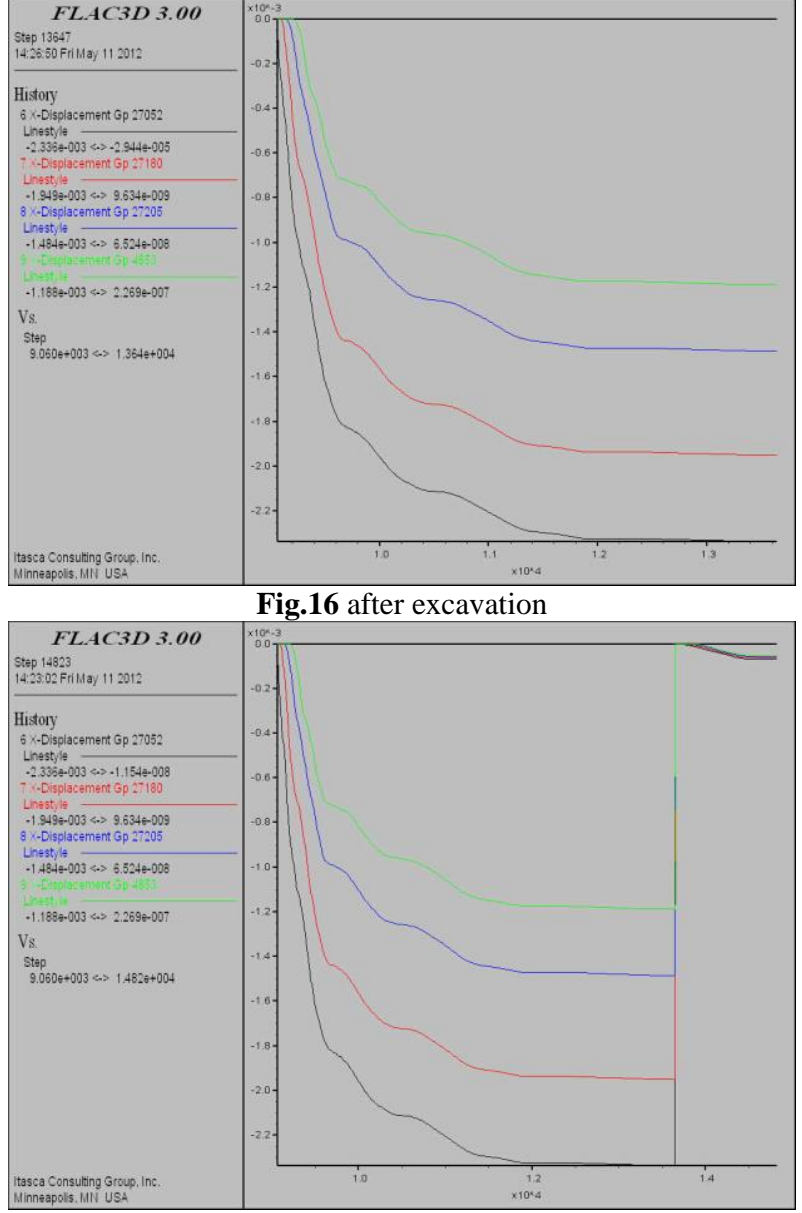

Fig.17 after Lining

3) Hole on both sides from the center of 5.8 meters, 8 meters, 11 meters, 14 meters at the vertical displacement
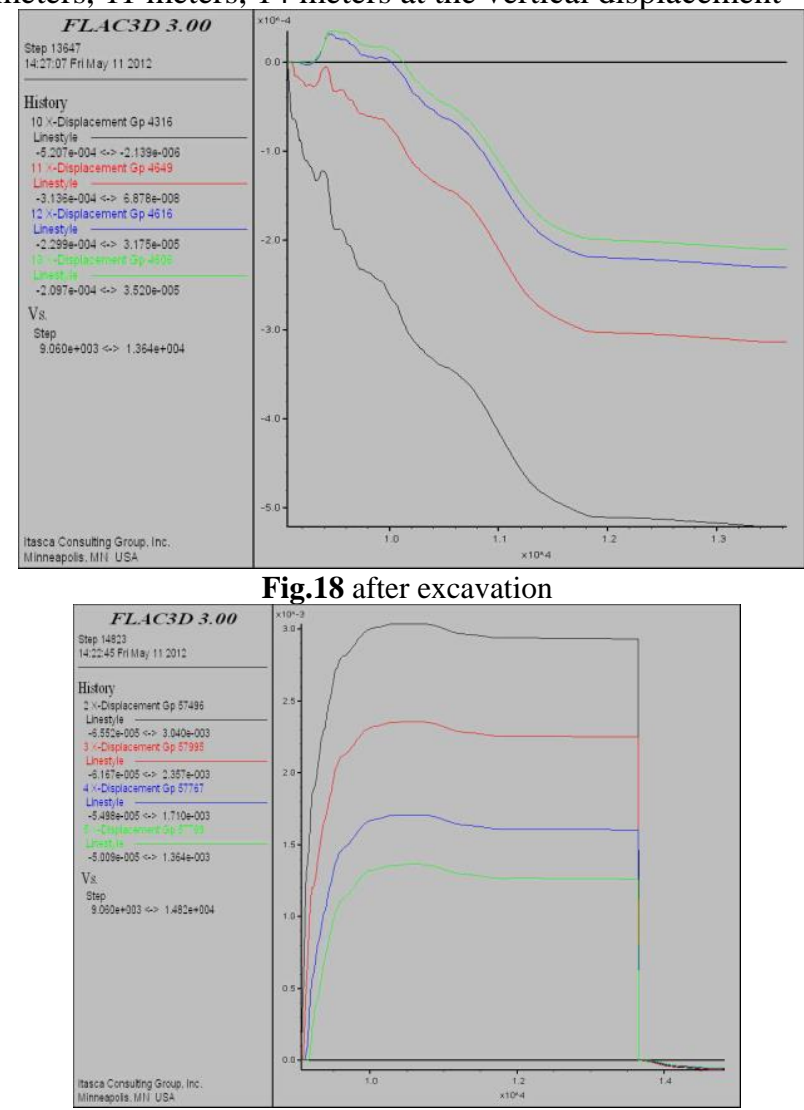

Fig.19 after Lining 
4) Hole on both sides from the center of the circle 5.8 meters, 8 meters, 11 meters, 14 meters at the horizontal displacement ( $\mathrm{z}$ direction)

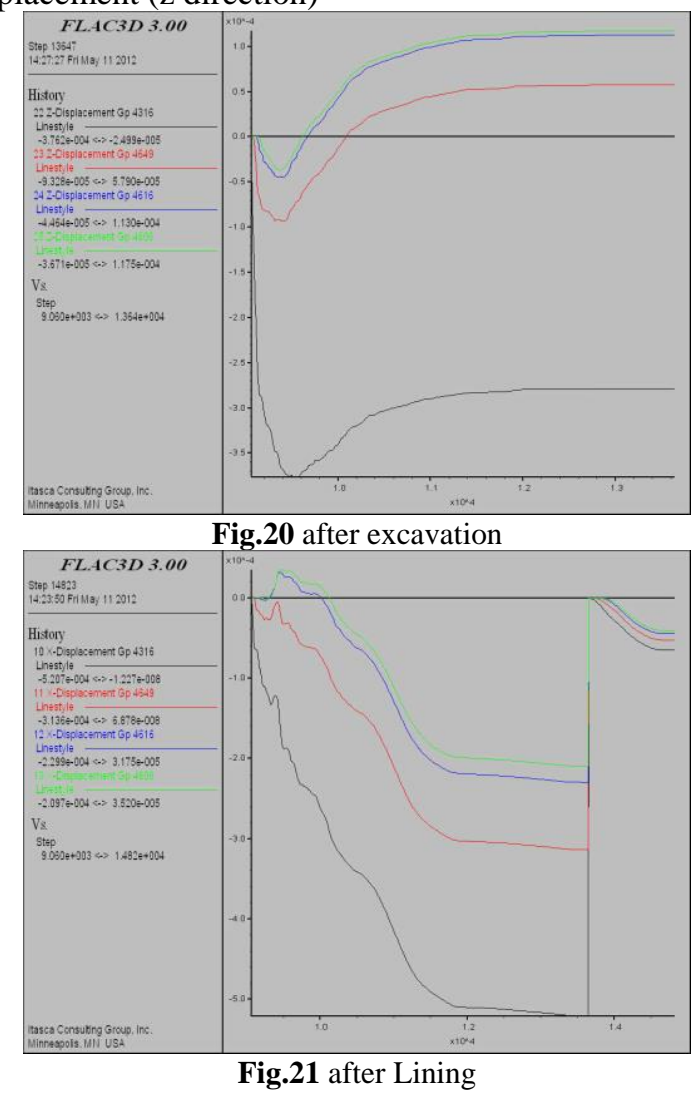

It can be seen from the figure that the closer the place to excavation, the greater the displacement, because the closer to the excavation position, the greater the stress release, the greater the impact of excavation and unloading. After the lining is applied, it can be seen from the figure that the displacements at all monitoring points are significantly reduced. Therefore, in tunnel excavation, the lining should be applied in time to ensure the stability of rock around the tunnel.

\section{Conclusion}

The numerical simulation software is used to carry out numerical excavation and lining calculation of spillway tunnel of a hydropower station. The calculation results show that the maximum displacement at the top of tunnel after excavation is $-2.34 * 10^{-3} \mathrm{~m}$ and the cave bottom is $2.38 * 10^{-3} \mathrm{~m}$. Displacement $-6.8 * 10^{-5} \mathrm{~m}$, indicating that after the lining is applied, the displacement of the perimeter of the tunnel decreases obviously and the stability of the rock around the tunnel has been improved obviously. The maximum principal stress of the perimeter of the tunnel is -1.21 Mpa and -1.04 Mpa after lining, After the excavation, the plastic zone of the surrounding rock and the surrounding rock near the fault have a larger range, and the range of the plastic zone obviously decreases after the lining is applied. The analysis shows that after the lining is applied, the displacement, stress and plastic zone of the surrounding rock of tunnel are improved, which can ensure the stability of the surrounding rock after tunnel excavation.

\section{References}

1. Wang Mengshu .21 century is the era of great development of tunnels and underground space [J]. West -China Exploration Engineering, 2000,01: 7-8.

2. Gao Qian, Qiaolan, Wu Shunchuan, Yang Suzhen. Underground Engineering System Analysis and Design [M]. Beijing: China Building Materials Industry Press, 2005.

3. WANG Zhen, SHEN Shun, PENG Yu, HUANG Wei. Layout Design of Flood Discharge Buildings in Bodui Hydropower Station [J]. Zhejiang Hydrotechnics, 2017,45 (05): 54-56.

4. Yang Xun. Construction and Management of Bodui Hydropower Station Project [A] .Architecture and Technology and Management Organizing Committee .Architecture and Technology and Management Symposium in November 2015 Proceedings [C]. "Building Technology and Management" Section Committee: 2015: 2.

5. Ni Cangna. Study on formation and engineering characteristics of glacial till, Bodui Hydropower project [J]. Northwest Water Resources, 2014, (05): 14-17.

6. Wang Yonghong, Gao Jian.Application of Controlled Cement Grouting in Cofferdam Seepage Control Project of Bodui Hydropower Station in Tibet [J]. Sichuan Water Power, 2014,33 (02): 65-67 $+79+172$.

7. MA Zhi-fa, SHI Guang-yu, SUI Wei, GUO Hong-juan.Study on Mixture Ratio of Asphalt Concrete at Bodui Hydropower Station [J]. Northeast Water Conservancy and Electric Power, 2013,31 (12): 52-55.

8. Peng Wenbin. FLAC3D practical tutorial [M]. Beijing: Mechanical Industry Press, 2007.

9. Chen Yumin, Xu Dingping. FLAC3D Foundation and Engineering [M]. Beijing: China Water Power Press, 2008. 